\title{
Effect of high flow nasal cannula on peripheral muscle oxygenation and hemodynamic during paddling exercise in patients with chronic obstructive pulmonary disease: a randomized controlled trial
}

\author{
Tien-Pei Fang ${ }^{1,2}$, Yen-Huey Chen ${ }^{2,3,4}$, Hsiu-Feng Hsiao, ${ }^{3,4}$, Hsiu-Ying Cho ${ }^{3,4}$, Ying-Huang Tsai ${ }^{3,5}$, \\ Chung-Chi Huang ${ }^{3,5}$, Meng-Jer Hsieh ${ }^{3,6}$, Huang-Pin $\mathrm{Wu}^{7}$, Hui-Ling $\mathrm{Lin}^{1,2,3}$ \\ ${ }^{1}$ Department of Respiratory Therapy, Chiayi Chang Gung Memorial Hospital, Chiayi; ${ }^{2}$ Department of Respiratory Therapy, Chang Gung Technical \\ University, Chiayi; ${ }^{3}$ Department of Respiratory Therapy, Chang Gung University, Taoyuan; ${ }^{4}$ Department of Respiratory Therapy, ${ }^{5}$ Department of \\ Pulmonary and Critical Care Medicine, Linkou Chang Gung Memorial Hospital, Taoyuan; ${ }^{6}$ Division of Pulmonary and Critical Care Medicine, Chiayi \\ Chang Gung Memorial Hospital, Chiayi; ${ }^{7}$ Department of Pulmonary and Critical Care Medicine, Keelung Chang Gung Memorial Hospital, Keelung \\ Contributions: (I) Conception and design: HL Lin, TP Fang; (II) Administrative support: HF Hsiao, CC Huang, HP Wu, YH Tsai; (III) Provision of \\ study materials or patients: All authors; (IV) Collection and assembly of data: HL Lin, HY Cho; (V) Data analysis and interpretation: HL Lin, YH \\ Chen, TP Fang; (VI) Manuscript writing: All authors; (VII) Final approval of manuscript: All authors. \\ Correspondence to: Hui-Ling Lin. Department of Respiratory Therapy, Chang Gung University, 259 Wen-Haw 1st Rd., Guishan, Taoyuan. \\ Email: huilingrrt@gmail.com.
}

Background: Exercise training for patients with chronic obstructive pulmonary disease (COPD) improves their endurance and oxygenation. Supplemental oxygen delivered by high flow nasal cannula (HFNC) reportedly improves the clinical outcomes during high-intensity exercise. However, the physical benefits of the provision of supplemental oxygen with HFNC for the improvement of exercise performance have not been fully investigated. This randomized trial aimed to evaluate the effect of HFNC on the hemodynamic status and peripheral muscle microcirculation during exercise training.

Methods: In this multicenter, randomized controlled parallel two-group study, 32 patients with moderate to severe COPD were randomly assigned into the nasal cannula (NC) group ( $\mathrm{n}=15)$ with a flow rate of $2-3 \mathrm{~L} / \mathrm{min}$ or the HFNC group ( $\mathrm{n}=17$ ) with a flow rate of $45 \mathrm{~L} / \mathrm{min}$ for twelve $40 \mathrm{~min}$ exercise training sessions.

Results: The mean cardiac index (CI) and stroke volume (SV) of the NC group in the first session were significantly lower than those of the HFNC group $\left(3.68 \pm 0.76\right.$ vs. $4.5 \pm 0.76 \mathrm{~L} / \mathrm{min} / \mathrm{m}^{2}, \mathrm{P}=0.014 ; 63.03 \pm 9.87$ vs. $74.22 \pm 19.48, \mathrm{P}=0.002$, respectively). The systemic vascular resistance (SVR) of the NC group was significantly lower in the seventh session than in the first session $\left(891 \pm 287\right.$ vs. $1,138 \pm 381 \mathrm{dyn}-\mathrm{s} / \mathrm{cm}^{5}$, respectively, $\mathrm{P}=0.048$ ). The mean deoxyhemoglobin level was higher in the HFNC group in the $1^{\text {st }}$ session and lower in the $12^{\text {th }}$ session $(1.09 \pm 9.04$ vs. $7.3 \pm 7.3 \mu \mathrm{m}, \mathrm{P}=0.046)$. The COPD Assessment Test score, Modified Medical Research Council scale score, maximum inspiratory pressure (MIP), and maximum expiratory pressure were different within and between the groups.

Conclusions: HFNC, with a lower oxygen concentration than that used with a traditional NC, yielded lower deoxygenated hemoglobin levels after 12 suboptimal exercise training sessions. In contrast, the higher oxygen concentration delivered by NC reduced SVR. The COPD assessment score improved on exercise training, regardless of the supplemental oxygen delivery method.

Keywords: High-flow nasal cannula oxygen therapy; pulmonary rehabilitation (PR); exercise training; muscle perfusion; hemodynamics

Submitted Nov 26, 2019. Accepted for publication Feb 11, 2020.

doi: $10.21037 /$ atm.2020.03.87

View this article at: http://dx.doi.org/10.21037/atm.2020.03.87 


\section{Introduction}

Pulmonary rehabilitation (PR) has been proven to offer physiological benefits and reduce symptoms in patients with chronic obstructive pulmonary disease (COPD) (1-3). Exercise training in a PR program for patients with COPD improves their muscle strength, exercise endurance, oxygenation, and efficiency of skeletal muscle use while reducing dynamic hyperinflation (2). However, patients with COPD frequently encounter a premature interruption of exercise due to dyspnea, resulting in exercise intolerance and lower compliance to the exercise training. Exercise intolerance may be attributed to peripheral muscle dysfunction and airflow limitation (4). Oxygen uptake by the exercising muscles might be a primary factor in exercise intolerance. When a healthy person exercises, the oxygen supplied to the working muscles exceeds its consumption by increasing pulmonary ventilation to increase arterial oxygen saturation and cardiac output (CO), resulting in increased oxygen content and delivery. Patients with COPD have impaired oxygenation and hindered oxygen transport, resulting in decreased exercise capacity. Supplemental oxygen during exercise for patients with COPD increases arterial oxygen partial pressure and reduces carotid body stimulation resulting in a lower requirement for pulmonary ventilation, the workload of respiratory muscles, dyspnea sensation, and less pulmonary vascular contraction. Supplemental oxygen improves the exercise performance of PR participants by reducing dyspnea sensation, lowering hypoxic drive ventilation, and delaying lactate acidosis in short- and long-term exercise training (5).

Some strategies, such as high flow nasal cannula (HFNC), non-invasive ventilation, and heliox, have been proposed to enhance exercise performance $(6,7)$. The clinical outcomes reported in studies using supportive therapies during exercise have varied. For instance, supplemental oxygen enabled higher-intensity exercise, improved exercise endurance, and reduced dyspnea in patients with nonhypoxemic moderate to severe COPD during exercise training $(8,9)$. However, a recent systematic review reported that supplemental oxygen during exercise training in patients with COPD did not improve exercise capacity, dyspnea scores, or quality of life, although the evidence quality was weak (4). Heliox, a gas with lower density than air and oxygen, generates less airway resistance than air and thereby requires less energy to use breathing muscles. Previous studies have shown that inhaled heliox reduces respiratory muscle power, increases quadriceps muscle oxygen, and relieves dyspnea sensations during nearmaximal exercise (10-12).

Among the device options for oxygen therapy, humidified heated HFNC has gained attention in the last decade (13). HFNC reportedly increases oxygenation and wash out $\mathrm{CO}_{2}$ in the dead space of the upper airways. Additionally, HFNC provides stable $\mathrm{FiO}_{2}$ with less dilution by the entrained air gas. When oxygen is heated and humidified to $37^{\circ} \mathrm{C}$ with $100 \%$ relative humidity, the irritation of anhydrous high gas flow to the nose can be reduced, resulting in greater user tolerance. HFNC studies have focused more on the benefit of treating critically ill patients, and HFNC has recently been used to treat COPD patients in chronic conditions (14-17). The application of HFNC in severe COPD patients during maximum workload exercise testing was reportedly associated with better clinical outcomes, such as improved arterial oxygen saturation $\left(\mathrm{SaO}_{2}\right)$ levels and reduced symptoms (17). However, the physical benefit of supplemental oxygen with HFNC in exercise performance has not been fully investigated.

We hypothesized that supplement oxygen with HFNC might reduce the cardiac workload and increase oxygenation in the working muscles during exercise. This randomized trial aimed to noninvasively evaluate the effect of HFNC on the hemodynamic and peripheral muscle microcirculation status during exercise training in a PR program.

\section{Methods}

This prospective multi-center randomized controlled parallel two-group study used concealed allocation. Due to differences in the appearance of the HFNC and NC devices, it was not possible to perform a double-blind study, and blinding was only applied to the assessors. This study was approved by the Ethics Committee of Chang Gung Medical Foundation, and informed consent was obtained from all participants. The trial was registered with the U.S. National Clinical Trial Registry database (NCT03237962).

\section{Study population}

COPD patients were referred to the PR program from the pulmonary outpatient clinics of the Keelung, Linkou, and Chiayi branches of Chang Gung Memorial Hospital between August 2016 and July 2018. The inclusion criteria were age $>55$ years, meeting the diagnostic criteria for COPD according to the Global Initiative for Chronic 
Obstructive Lung Disease (GOLD) guidelines, postbronchodilator forced expiratory volume in $1 \mathrm{~s}\left(\mathrm{FEV}_{1}\right) /$ forced vital capacity (FVC) ratio $<70 \%$, a medically stable condition (i.e., at least 4 weeks since the last exacerbation), and not a current smoker (18). The exclusion criteria were receiving home oxygen therapy, signs of infection, and comorbidities such as severe cardiovascular, neurological, or musculoskeletal conditions that were likely to affect performance during assessments or exercise training adversely.

\section{Randomization and sample size}

Participants who met the study inclusion criteria and completed the baseline assessments were randomly allocated to the nasal cannula (NC) or HFNC group. Each patient provided written informed consent, and the study was conducted in accordance with the Declaration of Helsinki. Equal numbers of participants were randomized to each group. A sealed opaque envelope was used to ensure allocation concealment of the randomly generated treatment by the principal investigator. Due to the differences in the appearance of the 2 oxygen delivery devices, only the investigators were blinded during data review and statistical analyses. The critical sample size was calculated using the data from a study by Nasis et al., and the mean change in $\mathrm{CO}$ of $0.8 \mathrm{~L} / \mathrm{min}$ (standard deviation, $0.4 \mathrm{~L} / \mathrm{min}$ ) between the control and intervention groups was identified as the minimal significant difference (19). The sample size was estimated by G-power software. To reach the $80 \%$ power required to detect significance at the $5 \%$ level, the estimated sample size was 22 participants, with an expected dropout rate of $20 \%$ and an allocation ratio of $1: 1$ for the minimum difference in the change of $\mathrm{CO}$ between the 2 groups.

\section{Training program}

The participants were randomly allocated to the following 2 groups: (I) NC treatment (Galmed Inc., Yilan, Taiwan) group, with a flow of $2-3 \mathrm{~L} / \mathrm{min}$ titrated to maintain a pulse oxygen saturation $\left(\mathrm{SpO}_{2}\right)>92 \%$ throughout the exercise training; or (II) HFNC treatment (Great Group Medical Co., Ltd., Taiwan), with a flow of 30-45 L/min titrated according to the participant's tolerance and comfort and with the oxygen concentration adjusted to maintain a $\mathrm{SpO}_{2}$ $>92 \%$ throughout the exercise training. The gas flow and oxygen concentration provided by the high flow system were verified by a flow meter and oxygen analyzer.
The participants received a total of twelve 40-min exercise training sessions in the PR program ( 2 per week for 6 weeks). The exercise training sessions were organized as follows: warm-up exercise for $5 \mathrm{~min}$, followed by cardiopulmonary endurance training on a paddling ergometer (APT-5; Kibbutz Tzora, Israel) for $30 \mathrm{~min}$. Target training intensity was $60-80 \%$ of the age-predicted maximal heart rate or at the level of symptom limitation based on a Borg Dyspnea Scale rating of 3-5. The training program ended with cool-down for $5 \mathrm{~min}$ on a paddling ergometer without a set resistance.

\section{Outcome measurements}

The patients' demographic information was collected, which included sex, age, height, weight, pulmonary function test reports, and inhaled medications. The primary outcome of our study was the change in cardiac index (CI) in the 2 groups. The secondary outcomes were hemodynamic changes and skeletal muscle microperfusion. The baseline of muscle oxygenation and hemodynamic parameters before exercise were measured before the start of the first exercise training. Other respiratory related parameters which included the maximum inspiratory pressure (MIP), COPD Assessment Test (CAT), Modified Medical Research Council (mMRC) scale score, and Borg Dyspnea Scale score were measured.

\section{Measurement process}

\section{Skeletal muscle blood microperfusion/oxygenation}

Peripheral muscle oxygenation of the right quadriceps muscle was evaluated using near infrared spectroscopy (NIRS) equipment (PortaLite, Artinis Medical Systems, Einsteinweg, The Netherlands) (20,21). The NIRS technique is based on the emission and reception of light with wavelengths of 760 and $850 \mathrm{~nm}$ in the near-infrared region of the spectrum on the tissue's surface. NIRS technology continuously measures the relative changes in muscle oxygenated hemoglobin $[\mathrm{oxy}(\mathrm{Hb})]$ to deoxygenated hemoglobin $[\operatorname{deoxy}(\mathrm{Hb})](21)$. The total hemoglobin [Total(Hb)], difference in oxygenated hemoglobin [diff(Hb)], tissue saturation index (TSI, \%) were calculated as follows:

$$
\begin{aligned}
& \operatorname{Total}(\mathrm{Hb})=\operatorname{oxy}(\mathrm{Hb})+\operatorname{deoxy}(\mathrm{Hb}) \\
& \operatorname{Diff}(\mathrm{Hb})=\operatorname{oxy}(\mathrm{Hb})-\operatorname{deoxy}(\mathrm{Hb})
\end{aligned}
$$


Page 4 of 12

$$
\mathrm{TSI}=\operatorname{oxy}(\mathrm{Hb}) / \operatorname{total}(\mathrm{Hb})
$$

The NIRS probe was calibrated prior to each testing session using a calibration block of known absorption and scattering coefficients. The probe was positioned on the vertical axis of the right thigh and attached to the skin using Velcro straps and tape (22). To avoid the effect of room light, the probe was fixed to the skin using a black band. The distance between the optodes and the receptor was $\geq 4 \mathrm{~cm}$ to allow a signal penetration of around $2 \mathrm{~cm} \mathrm{(23).}$ A sampling rate of $10 \mathrm{~Hz}$ was used for analog-to-digital conversion, and subsequent analyses were conducted. The continuous measures were taken every $10 \mathrm{~s}$ throughout the exercise in the $1^{\text {st }}, 7^{\text {th }}$, and $12^{\text {th }}$ sessions, 3 min before the exercise and $3 \mathrm{~min}$ after completion of the exercise. Parameters at the $1^{\text {st }} \mathrm{min}$ of exercise, $1 \mathrm{~min}$ at maximum exercise, and the last min of cool down were retrieved and averaged.

\section{Hemodynamic measurements}

Impedance cardiography was used for patients with COPD for non-invasive cardiac monitoring in previous studies and was recently validated with a comparison to the dye dilution method by Louvaris and associates (24). Impedance cardiography (PhysioFlow ${ }^{\mathrm{TM}}$; Manatec Biomedical, France) emits a high-frequency and low-amperage alternating electrical current via electrodes; 1 transmitting electrode and 1 receiving electrode were applied to the base of the neck on the left, while another transmitting electrode and receiving electrode were applied along the xyphoid area (25-27). Additionally, 2 electrodes were positioned to monitor a single electrocardiography signal. The current study employed the PhysioFlow to measure CO, CI, stroke volume (SV), systemic vascular resistance (SVR), and ejection fraction (EF). After careful skin preparation that included the application of a mildly abrasive gel and then cleaning with alcohol, 6 electrodes were placed according to the manufacturers' instructions: 2 on the neck on the left side (one vertically above the other over the carotid artery above the supraclavicular fossa); 2 anteriorly in the xiphoid region; and 2 in locations corresponding to the V1 and V6 positions used for conventional electrocardiogram (ECG) monitoring. The PhysioFlow software includes a realtime indication of signal quality (expressed as a percentage) and data with signal quality $<90 \%$ were excluded. The continuous measurements were taken every $1 \mathrm{~s}$ throughout the exercise in the $1^{\text {st }}, 7^{\text {th }}$, and $12^{\text {th }}$ sessions, 3 min before and $3 \mathrm{~min}$ after the exercise training. Parameters at the $1^{\text {st }}$ min of exercise, $1 \mathrm{~min}$ at maximum exercise, and the last min of cool down were retrieved and averaged

\section{Statistical analysis}

The data were analyzed using the Statistical Package for the Social Sciences (version 23; IBM Inc., NY, USA). Continuous variables are represented as median (interquartile range) and mean \pm standard deviation. The effective size was determined by partial eta-squared. Independent $t$-tests were used to examine the participants' basic characteristics and intergroup measurement differences. To compare within-patient exercise responses and the influence of oxygen devices, two-way repeatedmeasures analysis of variance (ANOVA) was conducted. Values of $\mathrm{P}<0.05$ were considered statistically significant.

\section{Results}

\section{Characteristics of the study population}

A total of 60 outpatients were referred to the PR program for eligibility screening between August 2016 and July 2018. A total of 44 participants were enrolled, and a total of 32 participants completed the 12 exercise training sessions and were included in the final analysis (Figure 1). The overall effect size analyzed by partial eta-squared $(\eta 2)$ was 0.77 with a $\mathrm{P}=0.037$, and a confidence interval (CI) of $87.28 \%$ power.

The baseline characteristics were similar between the 2 groups (Table 1). All participants were categorized as having moderate COPD based on the $\mathrm{FEV}_{1}$ severity according to the GOLD guidelines. The $\mathrm{SpO}_{2}$ before exercise training was similar between groups (median of $96 \%$ for both groups, $\mathrm{P}=0.710$ ). During the exercise, supplemental oxygen was titrated to maintain a $\mathrm{SpO}_{2}>92 \%$; the median oxygen flow was $2.8(2.0$ 4.0) $\mathrm{L} / \mathrm{min}$ in the NC group, whereas the oxygen concentration was $26.8 \%(22.0-29.0 \%)$ with oxygen flow at $36.0(30.0$ 45.0) $\mathrm{L} / \mathrm{min}$ in the HFNC group.

The baseline hemodynamic parameters were taken $1 \mathrm{~min}$ before the first session exercise, and the average SV, O, CI, and SVR were similar between 2 groups. The paddle resistance at peak exercise was $19.24 \pm 9.84$ watts for the $\mathrm{NC}$ group and $22.86 \pm 10.16$ watts for the HFNC group $(\mathrm{P}=0.218)$, while the intensity increments from the $1^{\text {st }}$ to $12^{\text {th }}$ sessions were 


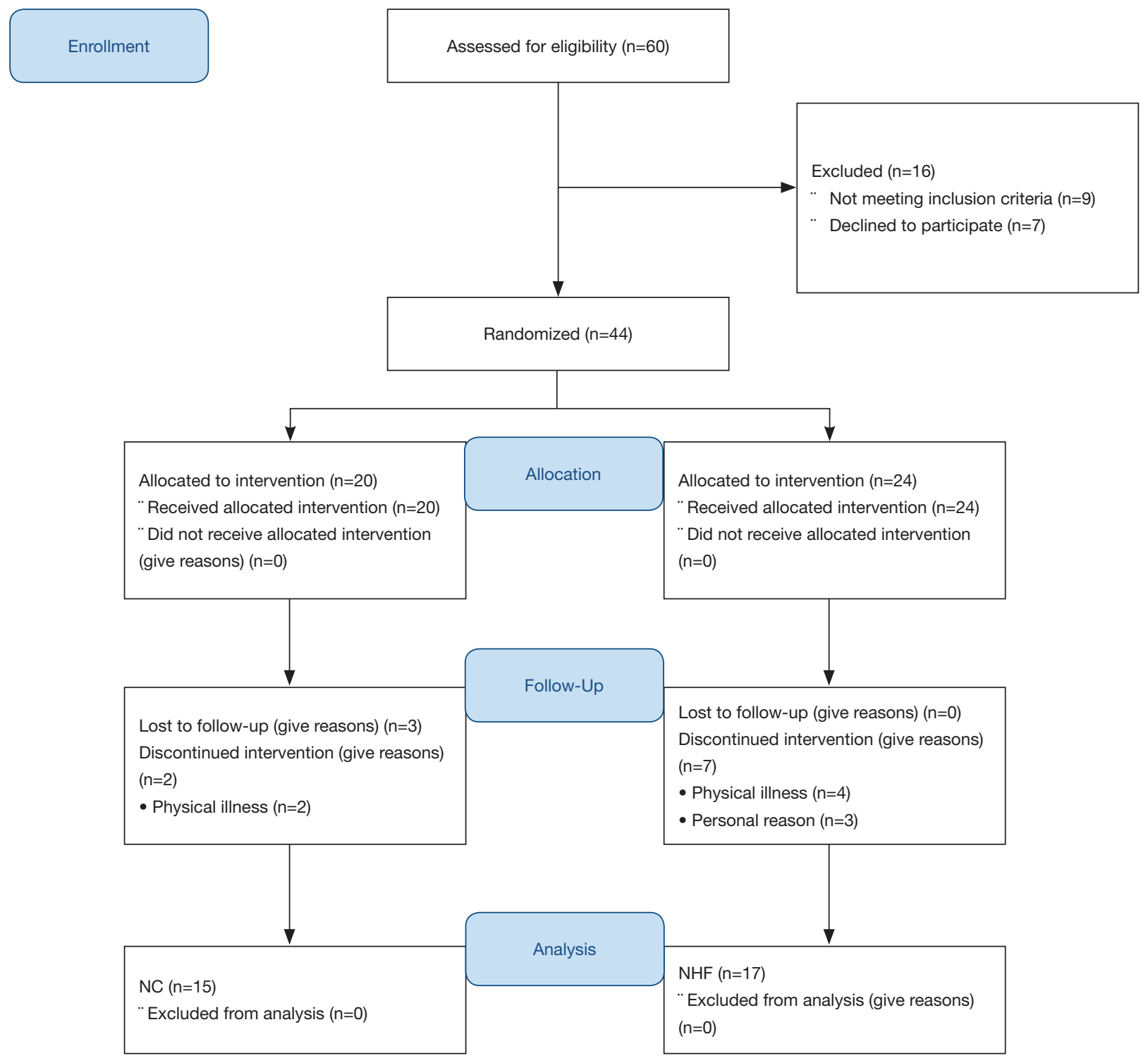

Figure 1 Flow chart for the study population.

$9.14 \pm 7.47$ watts for the $\mathrm{NC}$ group and $9.57 \pm 9.65$ watts for the HFNC group $(\mathrm{P}=0.852)$.

\section{Respiratory assessment}

The comparisons in the training intensity, symptoms, and respiratory parameters between the 2 groups are listed in Figure 2. The respiratory parameters were similar between the 2 groups in the $1^{\text {st }}, 7^{\text {th }}$, and $12^{\text {th }}$ sessions. The CAT score decreased from $16.47 \pm 6.13$ to $10.93 \pm 5.75(\mathrm{P}=0.038)$ in the $\mathrm{NC}$ group and from $17.35 \pm 5.75$ to $11.94 \pm 4.49(\mathrm{P}=0.006)$ in the HFNC group, yet no significant intergroup difference was found. The mMRC scale scores decreased from 3.0 at baseline to 2.4 after exercise training in both groups $(\mathrm{P}=0.005)$. The Borg Dyspnea Scale scores did not differ between the 2 groups at the 3 measurement points. The MIP and MEP in the $\mathrm{NC}$ group improved significantly from the $1^{\text {st }}$ to $12^{\text {th }}$ session (47.00 \pm 20.03 vs. $64.00 \pm 22.44 \mathrm{cmH}_{2} \mathrm{O}, \mathrm{P}=0.086$; and $60.27 \pm 29.07$ vs. $7.73 \pm 27.45 \mathrm{cmH}_{2} \mathrm{O}, \mathrm{P}=0.248$, respectively); however, no intergroup difference was found.

\section{Hemodynamic measurements}

The hemodynamic measurements were retrieved and calculated 
Table 1 Basic characteristic of the participants

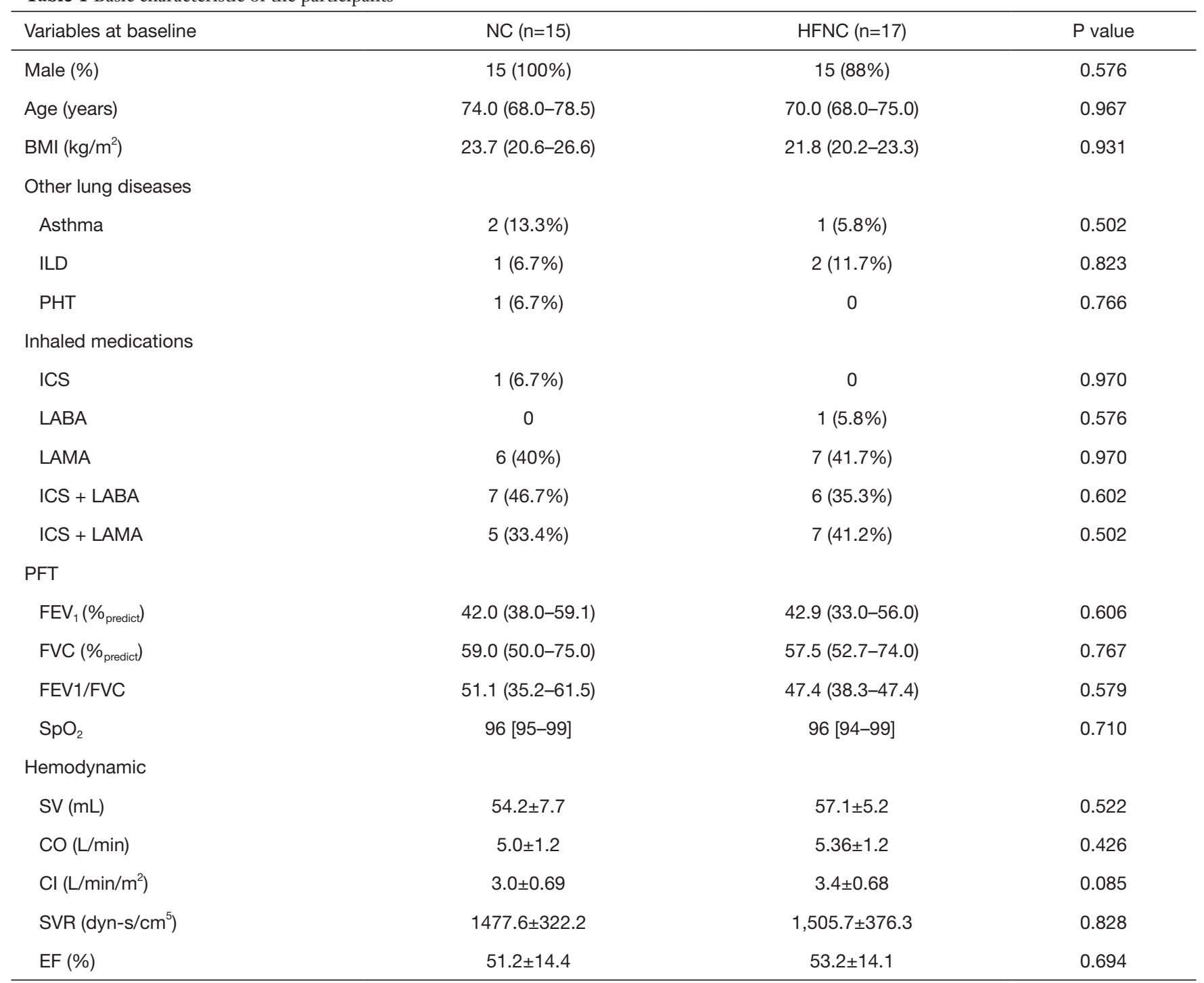

Data expressed as median (interquartile range) and mean \pm standard deviation. NC, traditional nasal cannula; HFNC, high-flow nasal cannula; BMI, body mass index; ILD, interstitial lung disease; PHT, pulmonary hypertension; ICS, inhaled corticosteroid; LABA, longacting beta-agonist; LAMA, long-acting muscarinic agent; $\mathrm{FEV}_{1}$, forced expiratory volume in $1 \mathrm{~s}$; $\mathrm{FVC}$, forced vital capacity; $\mathrm{SpO}_{2}$, oxygen saturation determined by pulse oximetry; SV, stroke volume; CO, cardiac output; $\mathrm{Cl}$, cardiac index; SVR, systemic vascular resistance; EF, ejection fraction.

as the average at first minute of warm-up, the last minute of peak exercise, and the last minute of cooling at the first minute of the $1^{\text {st }}, 7^{\text {th }}$, and $12^{\text {th }}$ sessions (Figure 3). During the first session, the CI of the $\mathrm{NC}$ group was significantly lower than that of the HFNC group $\left(3.68 \pm 0.76\right.$ vs. $\left.4.5 \pm 0.76 \mathrm{~L} / \mathrm{min} / \mathrm{m}^{2}, \mathrm{P}=0.014\right)$. The SV of the NC group was significantly lower than that of the HFNC group $(63.03 \pm 9.87$ vs. $74.22 \pm 19.48 \mathrm{~mL}, \mathrm{P}=0.002)$. The SVR of the NC group was significantly lower during the seventh session than that during the first session $(891.3 \pm 287.3$ vs. $\left.1,138.6 \pm 381.5 \mathrm{dyn}-\mathrm{s} / \mathrm{cm}^{5}, \mathrm{P}=0.048\right)$, and the intragroup comparison also showed a significant difference $(\mathrm{P}=0.047)$ in the NC group. No significant difference was observed in terms of $\mathrm{CO}, \mathrm{CI}$, or EF between the 2 groups at the 3 measurement points. Table 2 showed the change of physiological parameters at the peak exercise from the $1^{\text {st }}$ session to the $12^{\text {th }}$ session. The SV in HFNC group was significant reduced, whereas 

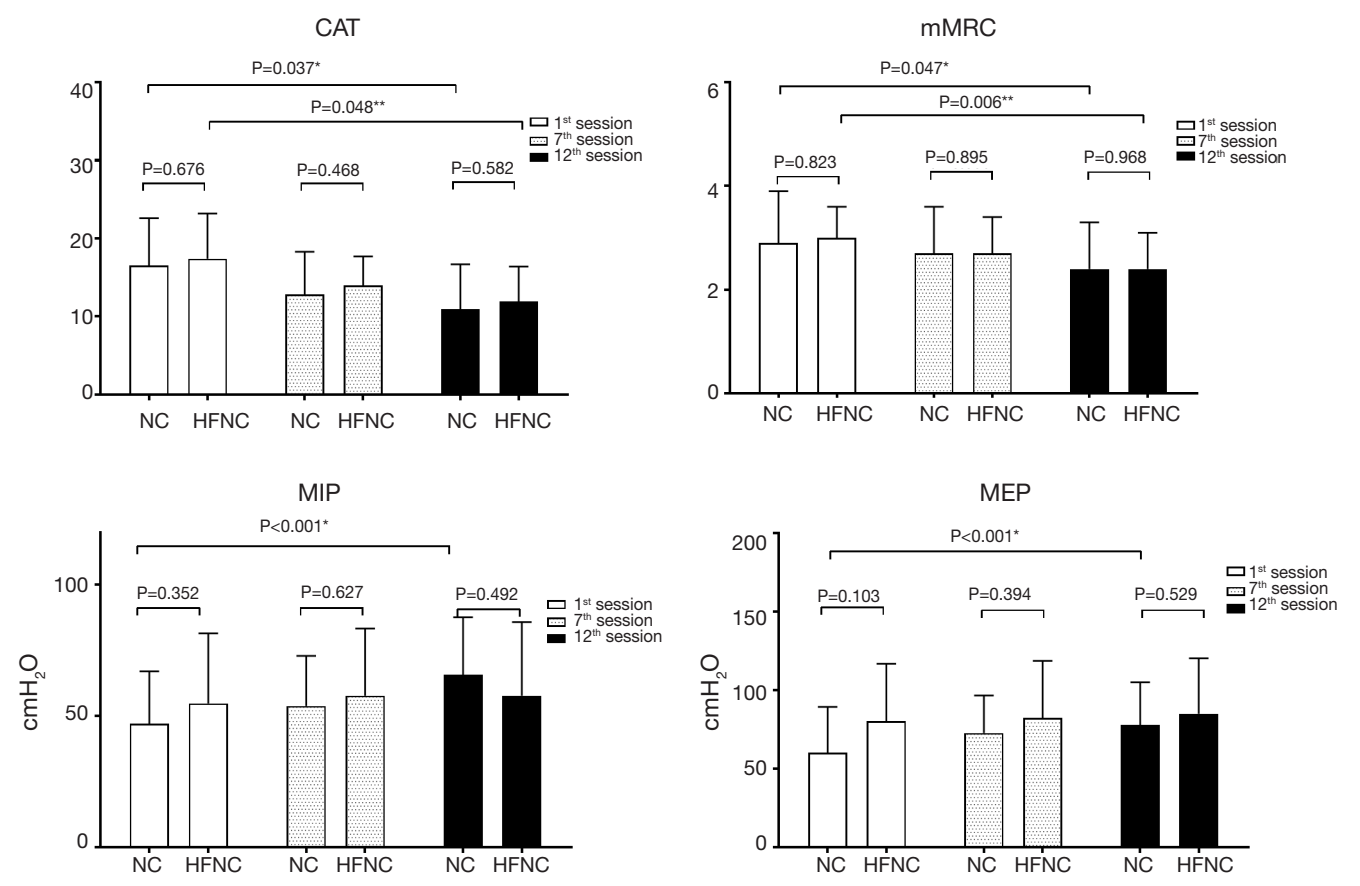

Figure 2 Comparisons of symptoms and respiratory parameters between the groups. CAT, COPD assessment test; mMRC, modified Medical Research Council; MIP, maximum inspiratory pressure; MEP, maximum expiratory pressure. *, significant difference between first and twelfth sessions with NC for all outcomes; ${ }^{* *}$, significant difference between first and twelfth sessions with HFNC for CAT and mMRC.

the SVR in NC group were significant lower.

\section{Skeletal muscle oxygenation}

The muscle microperfusion measurements were retrieved and calculated as the averages at first minute of warm-up, the last minute of peak exercise, and the last minute of cooling at the first minute of the $1^{\text {st }}, 7^{\text {th }}$, and $12^{\text {th }}$ sessions. Figure 3 illustrates the skeletal muscle oxygenation of the 2 groups. Oxygenation and perfusion of the quadriceps using the NIRS demonstrated that the TSI (Figure 4) of the NC group had a downward trend from the first session $(64.8 \% \pm 10.7 \%)$ to the seventh session $(57.7 \% \pm 12.67 \% ; \mathrm{P}=0.315)$. The $\operatorname{deoxy}(\mathrm{Hb})$ level was greater in the HFNC group than in the NC group in the $1^{\text {st }}$ session ( $4.48 \pm 8.48$ vs. $0.72 \pm 11.73 \mu \mathrm{m}$, respectively, $\mathrm{P}=0.04$ ), yet by the $12^{\text {th }}$ session, it was lower in the HFNC group than in the NC group $(1.09 \pm 9.04$ vs. $7.3 \pm 7.3 \mu \mathrm{m}$, respectively; $\mathrm{P}=0.046$ ) (Table 2). The $\operatorname{oxy}(\mathrm{Hb})$ and total $(\mathrm{Hb})$ levels were similar between and within groups.

\section{Discussion}

This study measured the effect of supplemental oxygen with HFNC during exercise training on hemodynamics and tissue perfusion in a PR program. The results showed that (I) HFNC reduces deoxy $(\mathrm{Hb})$ levels at maximal exercise after the intervention; (II) exercise with higher oxygen concentration delivered by NC might reduce SVR; (III) exercise training alleviated symptoms and improved inspiratory muscle strength regardless of the supplemental oxygen delivery method; and (IV) hemodynamic results were similar between groups after the completion of exercise training.

\section{Effects of HFNC during exercise}

Exercise training is limited in COPD patients because of the increased amount of ventilation, worsened dynamic hyperinflation, and increased work of breathing, causing dyspnea and respiratory muscle fatigue (28). A previous study reported that providing an $\mathrm{HFNC}$ of $20 \mathrm{~L} / \mathrm{min}$ to patients with severe COPD during exercise reduced dyspnea improved the breathing pattern, and increased exercise duration (29). In a double-blind cross-over trial conducted by Cirio et al. using HFNC with an oxygen concentration of $40 \%$ and a low of $55-60 \mathrm{~L} / \mathrm{min}$ in which 
Table 2 Changes in the physiological parameters at the peak exercise from the $1^{\text {st }}$ session to the $12^{\text {th }}$ session of exercise training

\begin{tabular}{lccc}
\hline Measurement & $\mathrm{NC}(\mathrm{n}=15)$ & $\mathrm{HFNC}(\mathrm{n}=17)$ & P value \\
\hline $\mathrm{SV}(\mathrm{mL})$ & $6.6 \pm 11.0$ & $-1.1 \pm 10.8$ & $0.027^{\star}$ \\
$\mathrm{CO}(\mathrm{L} / \mathrm{min})$ & $0.8 \pm 1.2$ & $0.6 \pm 1.6$ & 0.123 \\
$\mathrm{Cl}\left(\mathrm{L} / \mathrm{min} / \mathrm{m}^{2}\right)$ & $0.5 \pm 0.7$ & $0.02 \pm 9.4$ & 0.110 \\
$\mathrm{SVR}\left(\mathrm{dyn}-\mathrm{s} / \mathrm{cm}^{5}\right)$ & $-168.0 \pm 320.0$ & $63.2 \pm 3.74$ & $0.032^{*}$ \\
$\mathrm{EF}(\%)$ & $1.8 \pm 10.8$ & $3.2 \pm 10.5$ & 0.712 \\
$\mathrm{TSI}(\%)$ & $-1.7 \pm 5.2$ & $-0.9 \pm 3.3$ & 0.103 \\
$\mathrm{O}{ }_{2} \mathrm{Hb}(\mu \mathrm{m})$ & $-0.17 \pm 6.4$ & $1.16 \pm 7.6$ & 0.774 \\
$\mathrm{HHb}(\mu \mathrm{m})$ & $4.9 \pm 4.9$ & $-2.5 \pm 6.9$ & $0.031^{*}$ \\
$\mathrm{THb}(\mu \mathrm{m})$ & $4.8 \pm 8.5$ & $-1.4 \pm 11.3$ & 0.215 \\
$\mathrm{dHb}(\mu \mathrm{m})$ & $-5.1 \pm 7.6$ & $2.0 \pm 9.2$ & $0.021^{*}$ \\
\hline
\end{tabular}

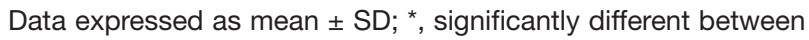
the 2 groups $(\mathrm{P}<0.05)$. NC, nasal cannula; HFNC, high-flow nasal cannula; SV, stroke volume; CO, cardiac output; $\mathrm{CI}$, cardiac index; SVR, systemic vascular resistance; EF, ejection fraction; TSI, tissue saturation index; $\mathrm{HHb}$, deoxygenated hemoglobin; $\mathrm{THb}$, total hemoglobin; $\mathrm{dHb}$, difference in oxygenated hemoglobin.

patients exercised at $75 \%$ maximum exercise capacity, exercise tolerance was significantly increased, saturation of the arterial blood was increased, and dyspnea was reduced (15). Our results showed a greater $\operatorname{diff}(\mathrm{Hb})$ [amount of $\operatorname{oxy}(\mathrm{Hb})>$ deoxy $(\mathrm{Hb})$; Figure 3], which indicated less oxygen consumption during submaximal exercise. Reduced dyspnea is speculated to be attributable to reduced oxygen consumption by the major exercising muscles. BarberanGracia and associates conducted an 8-week endurance exercise training in patients with COPD and healthy subjects (28). Their results indicated that aerobic training increased the muscle oxygen extraction ratio at the submaximal exercise level. Our results showed a similar TSI throughout the exercise training sessions, while the $\operatorname{deoxy}(\mathrm{Hb})$ level was significantly decreased in the HFNC group at the $7^{\text {th }}$ and $12^{\text {th }}$ sessions. With higher $\mathrm{FiO}_{2}$ delivered by $\mathrm{NC}$ in the first session, the $\mathrm{NC}$ group yielded a lower mean $\operatorname{deoxy}(\mathrm{Hb})$ level than the HFNC group. By the $12^{\text {th }}$ session, the deoxy $(\mathrm{Hb})$ level increased in the $\mathrm{NC}$ group but was significantly lower in the HFNC group. Inspiring higher gas flow in the HFNC group might have reduced oxygen consumption in the respiratory muscles and is speculated to have resulted in lower deoxy $(\mathrm{Hb})$ levels in the primary exercise muscles when performing exercise on the paddled ergometer. Furthermore, the stable TSI in the NC group with increased $\operatorname{deoxy}(\mathrm{Hb})$ level might be attributable to improved muscle perfusion, according to our results on the changes in SVR.

Base on the previous studies on the mechanism of HFNC (14), we hypothesized that HFNC would alleviate the cardiovascular workload and improve perfusion in working muscles. However, we have observed minimal physiological benefits. Further studies on the impact of HFNC during exercise could be tested by an exercise challenge with a cross-over design.

\section{Benefits of supplemental oxygen concentration}

Providing supplemental oxygen to patients with COPD during exercise training reduced the ventilation demand by reducing irritation of the peripheral chemoreceptors, thus increasing exercise tolerance. In the first session, the $\mathrm{CI}$ and SV in the HFNC group were significantly higher than those of the NC group. The higher CI and SV might be indicative of a reduced cardiac burden in the first session training in the HFNC group (30). Our results revealed that only the NC group experienced a physiological benefit of supplemental oxygen in reducing SVR. The participants in the NC group received oxygen at a flow of $2-4 \mathrm{~L} / \mathrm{min}$ with an estimated $\mathrm{FiO}_{2}$ of approximately $28-36 \%$, whereas the measured $\mathrm{FiO}_{2}$ in the HFNC group was approximately $26 \%$. The reduced SVR is speculated to have been produced by the higher oxygen concentration. Previous studies showed that supplemental oxygen reduces pulmonary vascular resistance in patients with pulmonary hypertension $(31,32)$. A limited review of the literature did not yield any evidence of the benefit of oxygen therapy in reducing SVR. The benefit of higher oxygen fraction delivered by HFNC on SVR during exercise warrants further investigations.

\section{Benefits of exercise training}

The participants in both groups had improved CAT scores after the $12^{\text {th }}$ exercise training session. The CAT is currently the most commonly used test for evaluating the health-related quality of life of COPD patients. Dodd et al. conducted a multi-center study comparing different evaluation tools for the outcomes of PR in patients with COPD $(33,34)$. Compared to the chronic respiratory questionnaire, incremental shuttle walk, and St. George test, the CAT was responsive to PR and more accurately discriminated between subjective response levels. In our study, improvement of the CAT score in both groups 

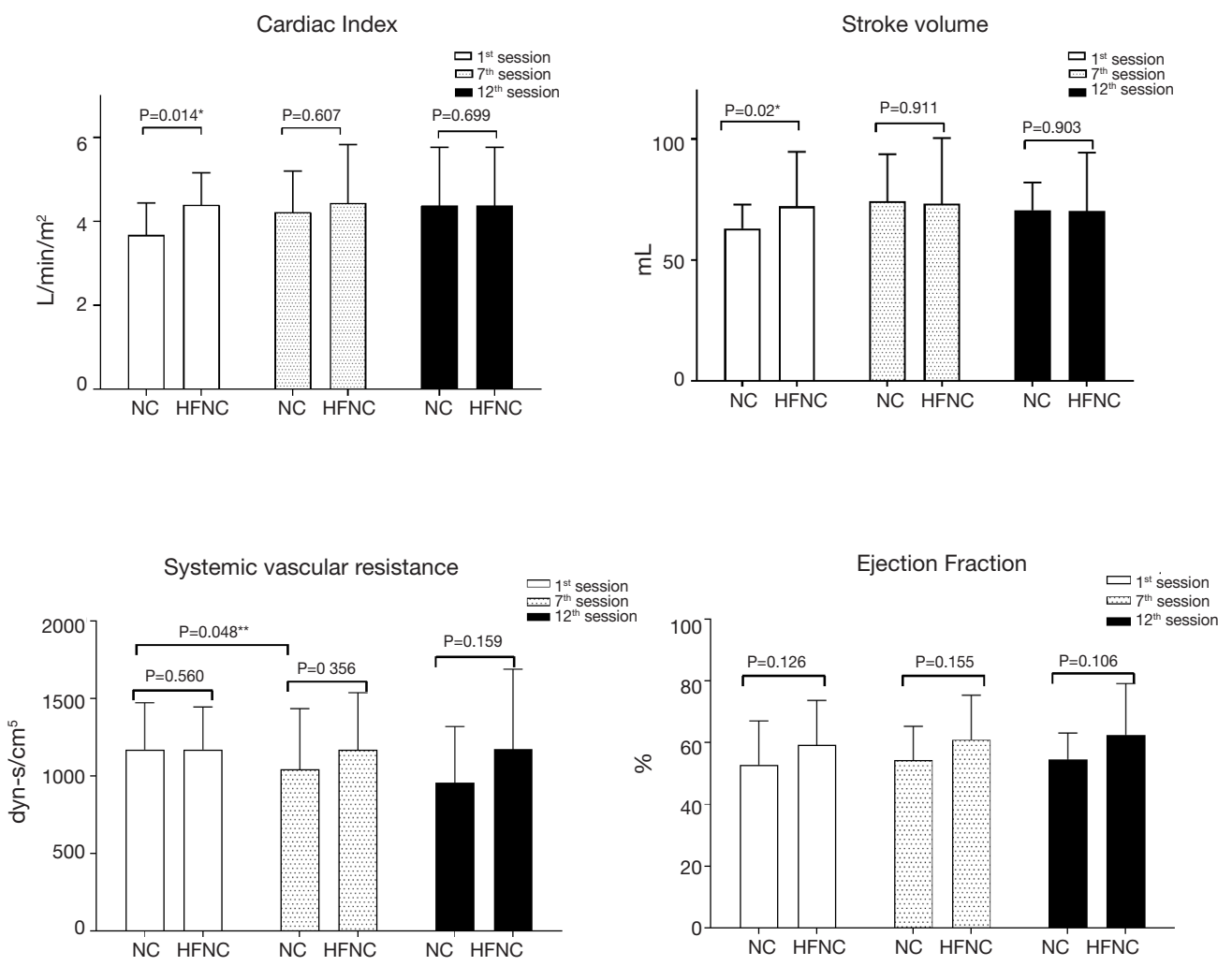

Figure 3 Comparisons of hemodynamic measurements. *, significant difference between NC and HFNC on the cardiac index and stroke volume in the first session; **, significant difference between first and seventh sessions for systemic vascular resistance.

indicated that participants in both groups benefited from improved health-related quality of life after 12 sessions of PR exercise training.

Mangine and associates investigated the effects of baseline muscle strength on adaptations to resistance training (35). The magnitude of these adaptations was dependent upon the individual baseline status and the specific characteristics of the training program. According to the principle of neural adaptation and recruitment of motor units, more physical adaptation occurred in weaker participants. Meanwhile, Evans and colleagues reported that individuals have weak respiratory muscles if the MIP was less than $60 \%$ of the predicted value (36). According to Evan's calculation, the $60 \%$ threshold for the $\mathrm{NC}$ group was $54 \mathrm{cmH}_{2} \mathrm{O}$, while that for the HFNC group was $57 \mathrm{cmH}_{2} \mathrm{O}$. In our study, the MIP of the NC group in the first session was lower than the threshold, which might have contributed to the great improvement seen after the exercise training. The MEP was measured with a forceful expiration and sustained for $1.0 \mathrm{~s}$ after patients inhaled at their maximum strength; therefore, the MIP and MEP results were correlated, with similar tendencies from the $1^{\text {st }}$ to $12^{\text {th }}$ sessions.

\section{Perspectives and significance}

Impaired muscle oxidative metabolism is a clinical characteristic of patients with COPD. Evidence shows that skeletal muscle dysfunction is a major determinant of reduced exercise capacity in patients with COPD. The application of HFNC decreases the concentration of $\operatorname{deoxy}(\mathrm{Hb})$ and may reduce the risk of muscle fatigue. Furthermore, using supplemental oxygen during exercise training is encouraged, even in non-hypoxic patients, to reduce the SVR.

\section{Limitations}

Some limitations of this study should be addressed. First, although the number of subjects was calculated with a 

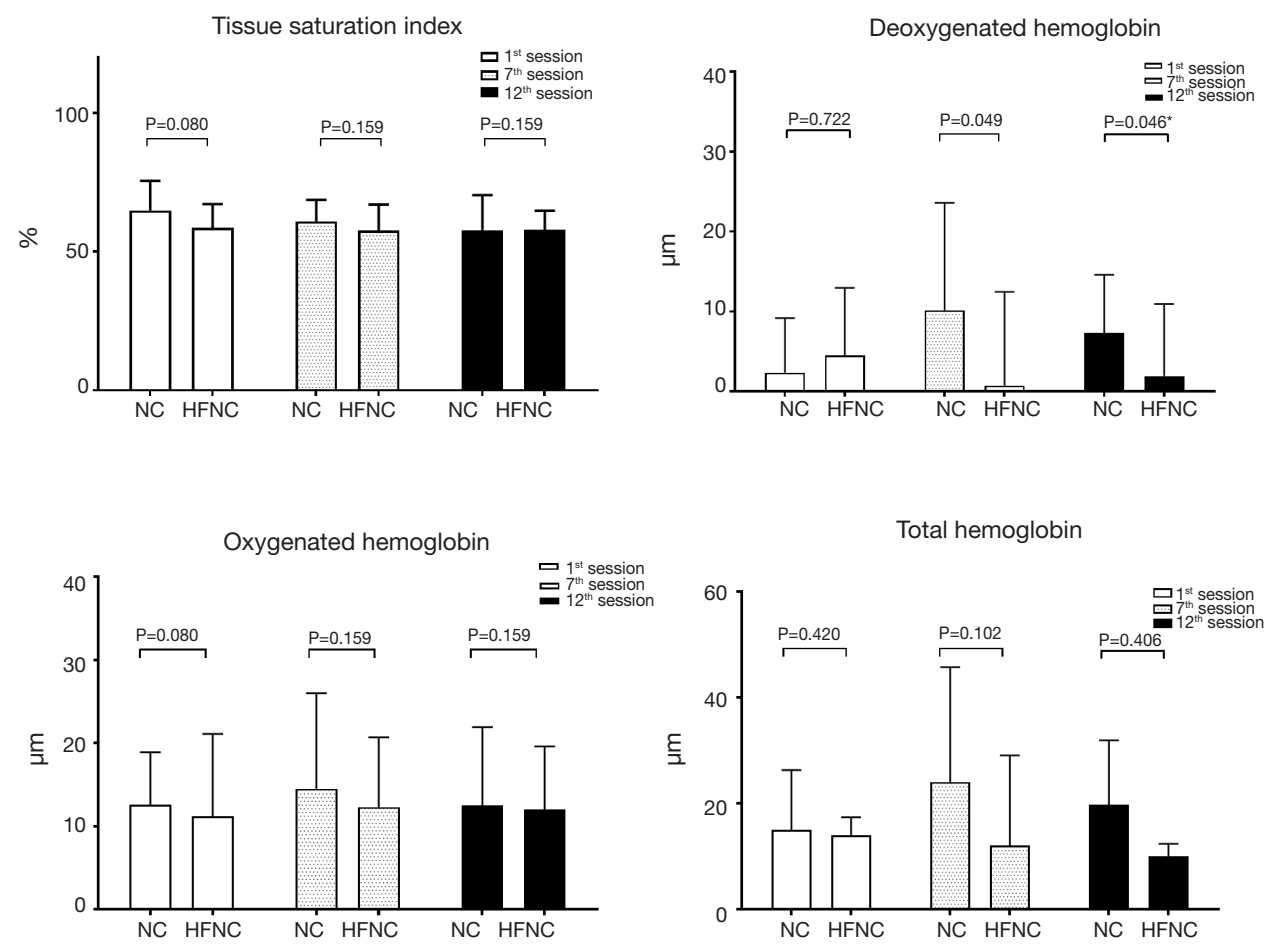

Figure 4 Comparisons of skeletal muscle oxygenation between the 2 groups. *, significant difference between NC and HFNC on the deoxygenated hemoglobin.

statistical power of $80 \%$, the sample size of this study was small. Thus, the results of this study may not be generalizable to the COPD population. However, this study demonstrated a reduction of $\operatorname{deoxy}(\mathrm{Hb})$ levels in the primary exercise muscles in the HFNC group, and research has shown that COPD patients have impaired contracting skeletal muscle oxygenation which can lead to the limitation in exercise (37). Second, the oxygen concentration of HFNC was measured using an oxygen analyzer attached to the machine, whereas the oxygen concentration of NC was estimated and fluctuated with the breathing pattern. Hence, oxygen concentration might have been overestimated. This study aimed to evaluate hemodynamics and muscle perfusion using a non-invasive measurement. Invasive procedures such as arterial blood oxygen partial pressure and saturation and hemodynamic measured by pulmonary catheterization might provide further information on patients' oxygenation during exercise. Some authors observed that impedance cardiography tends to overestimate values as compared to the thermodilution method, while others have observed that it underestimates them (38). Our results provided a trend of the changes during exercise, yet the absolute value might be altered depending on the machine used. To increase the compliance of subjects' participation in this study, this exercise training protocol was based on the routine PR program on exercise endurance training; therefore, the exercise intensity was not challenging and strenuous tests such as the cardiopulmonary exercise test were not performed. Further studies on the use of HFNC during higher-intensity exercise are warranted.

\section{Conclusions}

HFNC with higher gas flow and lower oxygen concentration produces quadriceps muscle oxygen consumption showing a lower $\operatorname{deoxy}(\mathrm{Hb})$ level during submaximal exercise. A reduced SVR was noted in the $\mathrm{NC}$ group that was possibly associated with higher oxygen concentration.

\section{Acknowledgments}

The authors thank Ms. Ting-Chang Hu for her assistance during this investigation, and Dr. James B. Fink for 
reviewing the manuscript.

Funding: This work was supported by the Ministry of Science and Technology, R.O.C. [grant numbers 105-2314B-182-041], and Chang Gung Memorial Hospital [grant numbers BMRPE83].

\section{Footnote}

Conflicts of Interest: The authors have no conflicts of interest to declare.

Ethical Statement: The authors are accountable for all aspects of the work in ensuring that questions related to the accuracy or integrity of any part of the work are appropriately investigated and resolved. This study was approved by the Ethics Committee of Chang Gung Medical Foundation, and informed consent was obtained from all participants.

Open Access Statement: This is an Open Access article distributed in accordance with the Creative Commons Attribution-NonCommercial-NoDerivs 4.0 International License (CC BY-NC-ND 4.0), which permits the noncommercial replication and distribution of the article with the strict proviso that no changes or edits are made and the original work is properly cited (including links to both the formal publication through the relevant DOI and the license). See: https://creativecommons.org/licenses/by-nc-nd/4.0/.

\section{References}

1. Almeida P, Rodrigues F. Exercise training modalities and strategies to improve exercise performance in patients with respiratory disease. Rev Port Pneumol 2014;20:36-41.

2. Andrianopoulos V, Klijn P, Franssen FM, el al. Exercise Training in Pulmonary Rehabilitation. Clin Chest Med 2014;35:313-22.

3. Rochester CL, Vogiatzis I, Holland AE, et al. An official American Thoracic Society/European Respiratory Society policy statement: enhancing implementation, use, and delivery of pulmonary rehabilitation. Am J Respir Crit Care Med 2015;192:1373-86.

4. Liu Y, Gong F. Determination of whether supplemental oxygen therapy is beneficial during exercise training in patients with COPD: A systematic review and meta analysis. Exp Ther Med 2019;18:4081-9.

5. Casaburi R, Garvey C. Special considerations for chronic obstructive pulmonary disease. In: Bayles MP, Swank
AM, editors. ACSM's Exercise Testing and Prescription. Philadelphia: Wolters Kluwer, 2018:470-90.

6. Ambrosino N, Strambi S. New strategies to improve exercise tolerance in chronic obstructive pulmonary disease. Eur Respir J 2004;24:313-22.

7. Vitacca M, Pietta I, Lazzeri M, et al. Effect of high-flow nasal therapy during exercise training in COPD patients with chronic respiratory failure: study protocol for a randomised controlled trial. Trials 2019;20:336.

8. Moga AM, de Marchie M, Saey D, et al. Mechanisms of non-pharmacologic adjunct therapies used during exercise in COPD. Respir Med 2012;106:614-26.

9. Spielmanns M, Fuchs-Bergsma C, Winkler A, et al. Effects of oxygen supply during training on subjects with copd who are normoxemic at rest and during exercise: A blinded randomized controlled trial. Respir Care 2015;60:540-8.

10. Voduc N, Tessier C, Sabri E, et al. Effects of oxygen on exercise duration in chronic obstructive pulmonary disease patients before and after pulmonary rehabilitation. Can Respir J 2010;17:e14-9.

11. Vogiatzis I, Habazettl H, Aliverti A, et al. Effect of helium breathing on intercostal and quadriceps muscle blood flow during exercise in COPD patients. Am J Physiol Regul Integr Comp Physiol 2011;300:R1549-59.

12. Louvaris Z, Zakynthinos S, Aliverti A, et al. Heliox increases quadriceps muscle oxygen delivery during exercise in COPDpatients with and without dynamic hyperinflation. J Appl Physiol 2012;113:1012-23.

13. Louvaris Z, Vogiatzis I, Aliverti A, et al. Blood flow does not redistribute from respiratory to leg muscles during exercise breathing heliox or oxygen in COPD. J Appl Physiol 2014;117:267-76.

14. Dysart K, Miller TL, Wolfson MR, et al. Research in high flow therapy: mechanisms of action. Respir Med 2009;103:1400-5.

15. Cirio S, Piran M, Vitacca M, et al. Effects of heated and humidified high flow gases during high-intensity constantload exercise on severe COPD patients with ventilatory limitation. Respir Med 2016;118:128-32.

16. Gaunt KA, Spilman SK, Halub ME, et al. Highflow nasal cannula in a mixed adult ICU. Respir Care 2015;60:1383-9.

17. Storgaard LH, Hockey HU, Laursen BS, et al. Longterm effects of oxygen-enriched high-flow nasal cannula treatment in COPD patients with chronic hypoxemic respiratory failure. Int J Chron Obstruct Pulmon Dis 2018;13:1195-205.

18. Bentsen SB, Wentzel-Larsen T, Henriksen AH, et al. Self- 
efficacy as a predictor of improvement in health status and overall quality of life in pulmonary rehabilitation-An exploratory study. Patient Educ Couns 2010;81:5-13.

19. Nasis I, Kortianou E, Vasilopoulou M, et al. Hemodynamic effects of high intensity interval training in COPD patients exhibiting exercise-induced dynamic hyperinflation. Respir Physiol Neurobiol 2015;217:8-16.

20. Ferrari M, Mottola L, Quaresima V. Principles, techniques, and limitations of near infrared spectroscopy. Can J Appl Physiol 2004;29:463-87.

21. Barstow TJ. Understanding near infrared spectroscopy and its application to skeletal muscle research. J Appl Physiol 2019; 126:1360-76.

22. Azevedo DP, Medeiros WM, de Freitas FF, et al. High oxygen extraction and slow recovery of muscle deoxygenation kinetics after neuromuscular electrical stimulation in COPD patients. Eur J Appl Physiol 2016;116:1899-910.

23. Ohya T, Aramaki Y, Kitagawa K. Effect of duration of active or passive recovery on performance and muscle oxygenation during intermittent sprint cycling exercise. Int J Sports Med 2013;34:616-22.

24. Louvaris Z, Spetsioti S, Andrianopoulos V, et al. Cardiac output measurement during exercise in COPD: A comparison of dye dilution and impedance cardiography. Clin Respir J 2019;13:222-31.

25. Charloux A, Lonsdorfer-Wolf E, Lampert E, et al. Exercise by a new impedance cardiography device: comparison with the direct Fick method. Eur J Appl Physiol 2000;82:313-20.

26. Richard R, Lonsdorfer-Wolf E, Charloux A, et al. Noninvasive cardiac output evaluation during a maximal progressive exercise test, using a new impedance cardiograph device. Eur J Appl Physiol 2001;85:202-7.

27. Chow SC, Shao J, Wang HS, et al. Sample size calculations in clinical research. 3rd edition. New York: Chapman and Hall/CRC Taylor \& Francis Group, 2017:89-95.

28. Emtner M, Porszasz J, Burns M, et al. Benefits of supplemental oxygen in exercise training in nonhypoxemic

Cite this article as: Fang TP, Chen YH, Hsiao HF, Cho HY, Tsai YH, Huang CC, Hsieh MJ, Wu HP, Lin HL. Effect of high flow nasal cannula on peripheral muscle oxygenation and hemodynamic during paddling exercise in patients with chronic obstructive pulmonary disease: a randomized controlled trial. Ann Transl Med 2020;8(6):280. doi: 10.21037/atm.2020.03.87 chronic obstructive pulmonary disease patients. Am J

Respir Crit Care Med 2003;168:1034-42.

29. Chatila $W$, Nugent $T$, Vance $G$, et al. The effects of high-flow vs low-flow oxygen on exercise in advanced obstructive airways disease. Chest 2004;126:1108-15.

30. Baty F, van Gestel AJ, Kern L, et al. Oxygen uptake recovery kinetics after the 6-minute walk test in patients with chronic obstructive pulmonary disease. Respiration 2016;92:371-9.

31. Roberts DH, Lepore JJ, Maroo A, et al. Oxygen Therapy improves cardiac index and pulmonary vascular resistance in patients with pulmonary hypertension. Chest 2001;120:1547-55.

32. Saadjian A, Philip-Joët F, Levy S, et al. Vascular and cardiac reactivity in pulmonary hypertension due to chronic obstructive lung disease: assessment with various oxygen concentrations. Eur Respir J 1992;5:525-30.

33. Dodd JW, Hogg L, Nolan J, et al. The COPD assessment test (CAT): response to pulmonary rehabilitation. A multicentre, prospective study. Thorax 2011;66:425-9.

34. Dodd JW, Marns PL, Clark AL, et al. The COPD Assessment Test (CAT): short- and medium-term response to pulmonary rehabilitation. COPD 2012;9:390-4.

35. Mangine GT, Gonzalez AM, Townsend JR, et al. Influence of baseline muscle strength and size measures on training adaptations in resistance-trained men. Int J Exerc Sci 2018;11:198-213.

36. Evans JA, Whitelaw WA. The assessment of maximal respiratory mouth pressures in adults. Respir Care 2009;54:1348-59.

37. Medeiros WM, Fernandes MC, Azevedo DP, et al. Oxygen delivery-utilization mismatch in contracting locomotor muscle in COPD: peripheral factors. Am J Physiol Regul Integr Comp Physiol 2015;308:R105-11.

38. Staelens A, Tomsin K, Grieten L, et al. Non-invasive assessment of gestational hemodynamics: benefits and limitations of impedance cardiography versus other techniques. Expert Rev Med Devices 2013;10:765-79. 